\title{
Role of Glycogen Synthase Kinase-3 $\beta$ in Neuronal Apoptosis Induced by Trophic Withdrawal
}

\author{
Michal Hetman, ${ }^{1,2}$ Jane E. Cavanaugh, ${ }^{1,2}$ David Kimelman, ${ }^{3}$ and Zhengui Xia ${ }^{1}$ \\ ${ }_{1}^{1}$ Toxicology Program in the Department of Environmental Health, and Graduate Program in Neurobiology and Behavior, \\ Graduate Program in Molecular and Cell Biology, Departments of 2 Pharmacology and ${ }^{3}$ Biochemistry, University of \\ Washington, Seattle, Washington 98195-7234
}

Glycogen synthase kinase- $3 \beta$ (GSK3 $\beta$ ) activity is negatively regulated by several signal transduction cascades that protect neurons against apoptosis, including the phosphatidylinositol-3 kinase ( $\mathrm{Pl}-3$ kinase) pathway. This suggests the interesting possibility that activation of GSK3 $\beta$ may contribute to neuronal apoptosis. Consequently, we evaluated the role of GSK3 $\beta$ in apoptosis in cultured cortical neurons induced by trophic factor withdrawal or by PI-3 kinase inhibition. Neurons were subjected to several apoptotic paradigms, including serum deprivation, serum deprivation combined with exposure to NMDA receptor antagonists, or treatment with PI-3 kinase inhibitors. These treatments all led to stimulation of GSK3 $\beta$ activity in cortical neurons, which preceded the induction of apoptosis. Expression of an inhibitory GSK3 $\beta$ binding protein or a dominant interfering form of GSK3 $\beta$ reduced neuronal apoptosis, sug- gesting that GSK3 $\beta$ contributes to trophic factor withdrawalinduced apoptosis. Furthermore, overexpression of GSK3 $\beta$ in neurons increased apoptosis, indicating that activation of this enzyme is sufficient to trigger programmed cell death. Although destabilization of $\beta$-catenin is an important physiological effect of GSK3 $\beta$ activation, expression of a mutant $\beta$-catenin that is not destabilized by GSK3 $\beta$ did not protect against apoptosis. We conclude that inhibition of GSK $3 \beta$ is one of the mechanisms by which Pl-3 kinase activation protects neurons from programmed cell death.

Key words: cortical neurons; glycogen synthase kinase-3 $\beta$; phosphatidylinositol-3 kinase; Akt; $\beta$-catenin; NMDA; glutamate; brain-derived neurotrophic factor; apoptosis; signal transduction
Differentiated cells, including neurons in the CNS, require the presence of survival factors to suppress the intrinsic cell death machinery and thereby avoid apoptosis (Raff et al., 1993; Park et al., 1997). The regulation of apoptosis by survival factors is therefore critical for normal development and proper functioning of multicellular organisms. In addition, abnormal apoptosis in CNS neurons may play a significant role in neurodegenerative diseases (Raff et al., 1993; Stefanis et al., 1997; Estus, 1998).

A number of survival factors for neurons have been identified, including serum, insulin-like growth factor-1, neurotrophins, and NMDA (Levi-Montalcini and Booker, 1960; D’Mello et al., 1993; Koh et al., 1995; Datta and Greenberg, 1998; F. X. Zhang et al., 1998). These factors activate the phosphatidylinositol-3 kinase (PI-3 kinase) pathway, which is one of several signal transduction pathways implicated in the survival of neurons (Yao and Cooper, 1995; Castellino and Chao, 1996; D'Mello et al., 1997; Dudek et al., 1997; Miller et al., 1997; Parrizas et al., 1997; Philpott et al., 1997; Yamada et al., 1997; Chao et al., 1998; Crowder and Freeman, 1998; F. X. Zhang et al., 1998; Hetman et al., 1999).

\footnotetext{
Received Nov. 22, 1999; revised Jan. 6, 2000; accepted Jan. 18, 2000.

This work was supported by Pilot Grant 1810 from the Royalty Research Fund at the University of Washington (Z.X.), and National Institute of Neurological Disorders and Stroke Grants NS37359 (Z.X.) and HD27262 (D.K). M.H. completed part of this work while on tenure of a fellowship award from the American Heart Association, Washington Affiliate. J.E.C. was supported by National Institutes of Health, Genetic Approaches to Aging Postdoctoral Training Grant 2 T32 AG0005721. We thank Dr. J. R. Miller for helpful discussion and Drs. M. Pap and G. M. Cooper for providing GSK3 $\beta$ constructs.

Correspondence should be addressed to Zhengui Xia, Department of Environmental Health, Box 357234, University of Washington, Seattle, WA 98195. E-mail: zxia@u.washington.edu.

Copyright (C) 2000 Society for Neuroscience $\quad 0270-6474 / 00 / 202567-08 \$ 15.00 / 0$
}

Although effectors downstream from PI-3 kinase that mediate neuron survival have not been completely identified, one likely candidate is protein kinase Akt (also known as PKB or RAC), a Ser/Thr-protein kinase that is activated by PI-3 kinase (Dudek et al., 1997; Franke et al., 1997; Hemmings, 1997; Kauffmann-Zeh et al., 1997; Kulik et al., 1997; Philpott et al., 1997; Crowder and Freeman, 1998; Murga et al., 1998). Akt phosphorylates and inhibits glycogen synthase kinase-3 $\beta$ (GSK3 $\beta$ ) (Cross et al., 1995; Moule et al., 1997), although GSK3 $\beta$ may also be regulated by other PI-3 kinase-dependent, but Akt-independent, pathways (Delcommenne et al., 1998; Kobayashi and Cohen, 1999). Because the PI-3 kinase-Akt pathway is neural-protective and negatively regulates GSK $3 \beta$ activity, GSK $3 \beta$ may be an important downstream proapoptotic target that contributes to apoptosis in neurons. Consistent with this hypothesis, Pap and Cooper (1998) demonstrated that GSK3 $\beta$ activity is required for apoptosis induced by inhibition of PI-3 kinase in Rat1 fibroblasts and neuronal-like PC12 cells. However, the role of GSK3 $\beta$ in apoptosis in primary cultured CNS neurons has not been evaluated. Here, we examined the activity of GSK3 $\beta$ after trophic withdrawal and quantitated the effect of inhibiting or stimulating the GSK $3 \beta$ pathway on induction of apoptosis. Our data indicate that this pathway plays an important role in the regulation of neuronal apoptosis.

\section{MATERIALS AND METHODS}

Materials. The following plasmids have been described previously: pON260 (Cherrington and Mocarski, 1989), expression constructs for Xenopus GSK3 $\beta$ binding protein (GBP) (Yost et al., 1998), rat GSK3 $\beta$ (Dominguez et al., 1995), and Myc-tagged expression vectors for wildtype and mutant Xenopus $\beta$-catenin (Pierce and Kimelman, 1995). The 
A.
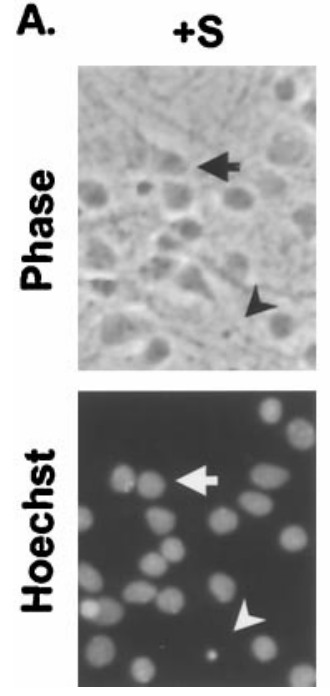

$-\mathbf{S}$
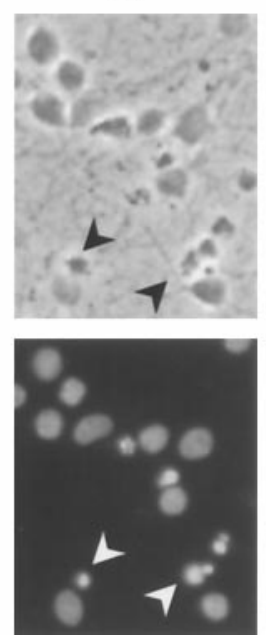

$-S+M K$
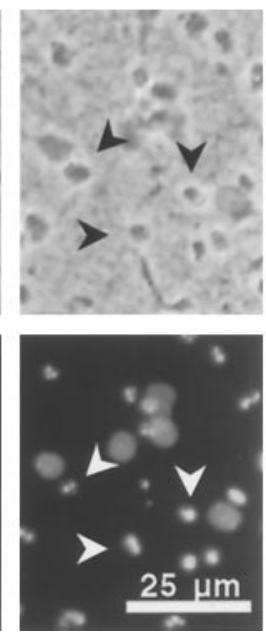

B.

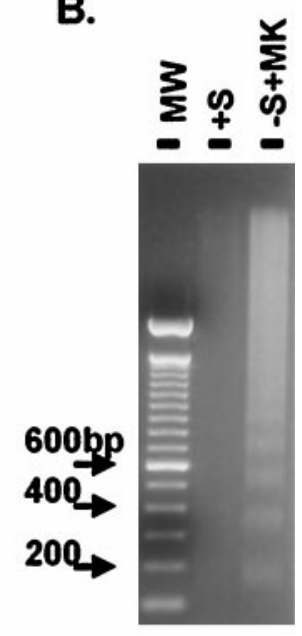

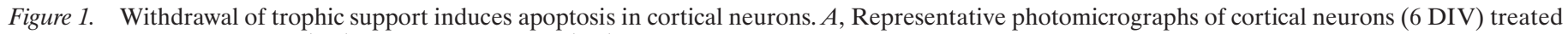

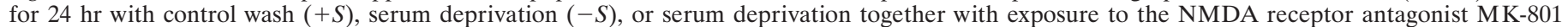

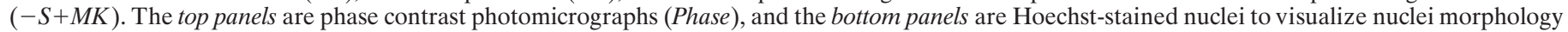

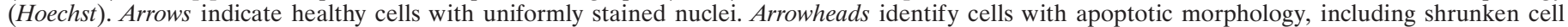

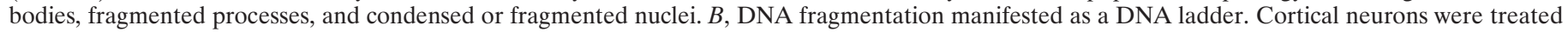

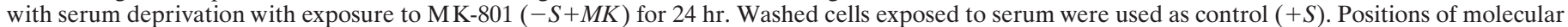

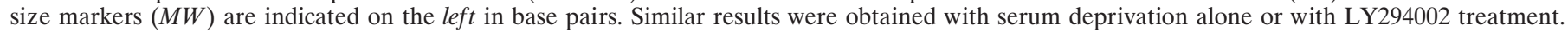

polyclonal anti-GSK3 $\beta$ antibody SC8257 used for immunoprecipitation was from Santa Cruz Biotechnology (Santa Cruz, CA); the anti-Akt and the anti-phospho-Ser 473 Akt antibodies were from New England Biolabs (Beverly, MA).

Cell culture and transfection. Cortical neurons were prepared from newborn Sprague Dawley rats as described previously (Xia et al., 1996; Hetman et al., 1999). The culture procedure used results in cell population consisting of at least $90 \%$ neurons at 5 days in vitro (DIV) (Hetman et al., 1999). Cortical neurons were transiently transfected at 3 DIV using a calcium-phosphate coprecipitation protocol (Xia et al., 1996) with modifications (Hetman et al., 1999).

Serum deprivation. Serum deprivation was performed with neurons at 4-6 DIV as described previously (Hetman et al., 1999). Briefly, cells were washed twice with serum-free basal medium Eagle (BME) (Sigma, St. Louis, MO) and incubated in serum-free BME supplemented with 35 $\mathrm{mm}$ glucose, $1 \mathrm{~mm}$ L-glutamine, $100 \mathrm{U} / \mathrm{ml}$ penicillin, $0.1 \mathrm{mg} / \mathrm{ml}$ streptomycin, and $2.5 \mu \mathrm{M}$ cytosine arabinoside in the presence or absence of NMDA receptor antagonists dizocilpine maleate (MK-801) $(10 \mu \mathrm{M})$ or 2-amino-5-phosphonovaleric acid (APV) $(100 \mu \mathrm{M})$. Control cells were washed similarly and then incubated for matched time points in serumcontaining conditioned medium with or without $10 \mu \mathrm{M}$ MK- 801 .

DNA ladder assay. To examine DNA cleavage, soluble cytoplasmic DNA was isolated from $4 \times 10^{6}$ cells and subjected to $1.8 \%$ agarose gel electrophoresis (Hockenbery et al., 1990; Hetman et al., 1999)

Quantitation of apoptosis by nuclear morphological changes. To visualize nuclear morphology, cells were fixed in $4 \%$ paraformaldehyde and stained with $2.5 \mu \mathrm{g} / \mathrm{ml}$ the DNA dye Hoechst 33258 (bis-benzimide; Sigma) (Hetman et al., 1999). Apoptosis was quantitated by scoring the percentage of cells with apoptotic nuclear morphology at the single cell level after Hoechst staining. Uniformly stained nuclei were scored as healthy, viable neurons. Condensed or fragmented nuclei were scored as apoptotic. To obtain unbiased counting, slides were coded, and cells were scored blind without knowledge of their previous treatment. Statistical analysis of the data were performed using one- or two-way ANOVA, followed by post hoc tests.

GSK3 $\beta$ kinase assay. GSK3 $\beta$ activity was quantitated using an immune complex kinase assay. Cell extracts were prepared as described previously (Xia et al., 1995); $200 \mu \mathrm{g}$ of protein extracts from each sample were incubated at $4{ }^{\circ} \mathrm{C}$ for $3-4 \mathrm{hr}$ with $0.8 \mu \mathrm{g}$ of the anti-GSK3 $\beta$ antibody prebound to protein $\mathrm{G}$ Sepharose (Sigma). The immunoprecipitates were washed twice with $50 \mathrm{~mm}$ Tris, $\mathrm{pH} 7.5,0.5 \mathrm{M} \mathrm{LiCl}$, and $1 \mathrm{mM}$ DTT and twice with $50 \mathrm{~mm}$ Tris, $\mathrm{pH} 7.5$, and $1 \mathrm{~mm}$ DTT. Kinase assays were then performed as described previously (Wang et al., 1994). The phosphory- lated peptide KRREILSRRPS(P)YR, with sequence derived from cAMP response element-binding protein, was used as the substrate for the kinase assay. Quantification of kinase activity was achieved by counting the amount of ${ }^{32} \mathrm{P}$ incorporated into the substrate.

Western analysis and immunostaining. Western blot analysis for antiphospho-Akt and immunostaining were performed as described previously (Xia et al., 1995, 1996; Hetman et al., 1999). Transfected cells were detected by immunostaining with a polyclonal antibody against $\beta$-galactosidase and Texas-Red-conjugated goat antibody to rabbit IgG. Cells transfected with the Myc epitope-tagged constructs were also immunostained with a monoclonal antibody to c-Myc (9E10), followed by fluorescein-conjugated goat antibody to mouse $\mathrm{IgG}$.

\section{RESULTS}

\section{Cortical neurons undergo apoptosis after serum withdrawal, serum withdrawal with inhibition of NMDA receptors, or after treatment with LY294002}

We have shown previously that cultured rat cortical neurons undergo apoptosis after serum withdrawal and that activation of the PI-3 kinase pathway is the dominant mechanism for serumdependent survival in these neurons (Hetman et al., 1999). The objective of this study was to test the hypothesis that inhibition of GSK $3 \beta$ through the PI-3 kinase-Akt pathway is one of the downstream mechanisms that mediate PI-3 kinase-dependent neuronal survival. Cortical neuron apoptosis was induced by serum deprivation, serum deprivation together with exposure to NMDA receptor antagonists MK-801 or APV, or treatment with LY294002, a pharmacological PI-3 kinase inhibitor (Vlahos et al., 1994). These three apoptotic paradigms are all expected to decrease PI-3 kinase signaling and were chosen to test the generality of our hypothesis.

Apoptosis was measured by monitoring neurite degeneration, cell body shrinkage, nuclei fragmentation or condensation, and DNA cleavage into oligonucleosome fragments manifested as "DNA laddering," hallmarks of apoptosis (Raff et al., 1993; Stefanis et al., 1997). Consistent with our previous report (Hetman et al., 1999), serum withdrawal or LY294002 treatment 


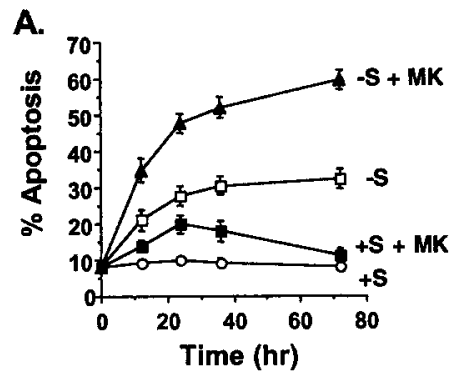

B.
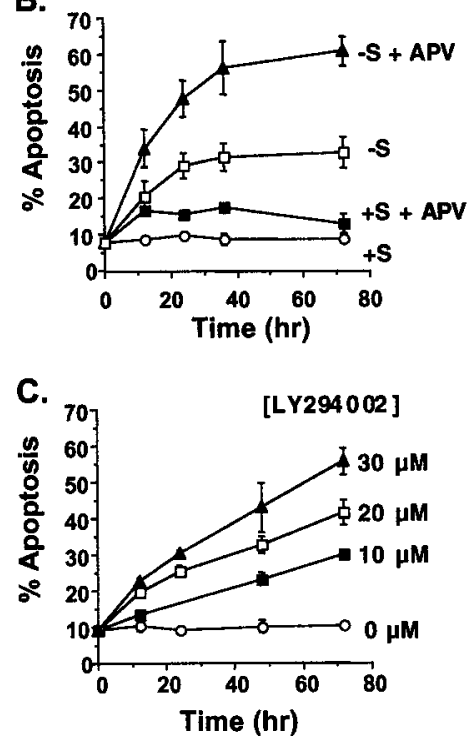

Figure 2. Quantification of apoptosis induced by trophic support withdrawal. Cortical neurons (6 DIV) were treated for $24 \mathrm{hr}$ with control wash $(+S)$ and serum deprivation $(-S)$ with or without exposure to MK-801 $(M K)(A)$ or APV $(B)$, or treated for $24 \mathrm{hr}$ with the PI-3 kinase inhibitor LY294002 in the presence of serum $(C)$. Averages of duplicate determinations in three $(A)$ or two $(B, C)$ independent experiments are shown. At least 1500 cells were scored for each data point in each experiment. Error bars represent SEM. Both MK-801 and APV significantly potentiated apoptotic death after serum withdrawal $(-S+M K$ or $-S+A P V$ compared with $-S)(p<0.0001$, ANOVA $)$.

induced apoptosis in cortical neurons (Figs. 1, 2). Because activation of NMDA receptors promotes survival in cultured cerebellar neurons (F. X. Z hang et al., 1998; Bhave et al., 1999), we also monitored apoptosis when serum withdrawal was combined with NMDA receptor antagonists MK-801 or APV (Watkins and Collingridge, 1989). Although MK-801 or APV treatment alone had little effect on neuronal survival in the presence of serum, they both greatly potentiated serum deprivation-induced apoptosis (Figs. 1, 2). These data suggest that both serum and NMDA receptor activity are required for optimal survival of cortical neurons. Furthermore, serum withdrawal combined with NMDA receptor antagonists should be a useful model to study mechanisms that regulate activity-dependent neuronal survival.

\section{Trophic withdrawal inhibits PI-3 kinase and activates GSK3 $\beta$}

To evaluate the effect of trophic withdrawal on PI-3 kinase, we assayed its activity by Western analysis using an antibody that only recognizes phosphorylated Akt because PI-3 kinase phosphorylates and activates Akt (Franke et al., 1997). Phosphorylation of Akt on Ser-473 is primarily dependent on PI-3 kinase

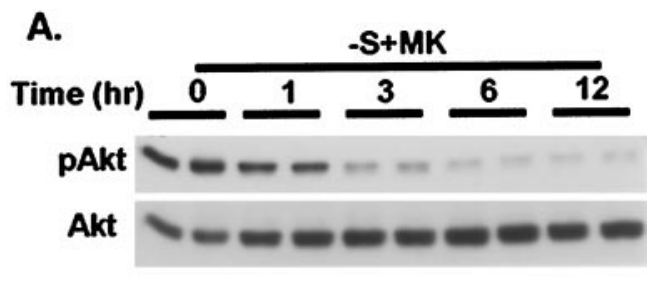

$30 \mu M$ LY294002

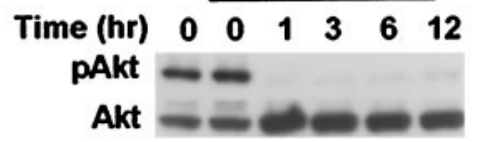

B.

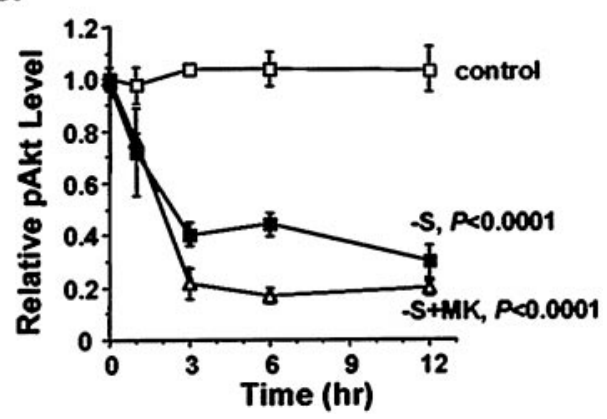

Figure 3. Inhibition of the PI-3 kinase-Akt pathway after trophic support withdrawal. Cortical neurons were treated for the indicated times with $30 \mu \mathrm{M}$ LY294002, serum deprivation $(-S)$, or serum deprivation with exposure to $10 \mu \mathrm{M}$ MK-801 $(-S+M K)$. Neurons washed similarly but then placed in serum-containing conditioned media were used as controls (control). A, Representative phospho-Akt Western analysis ( $p A k t)$ demonstrating reduced Akt phosphorylation at Ser-473, indicative of PI-3 kinase inhibition. The blots were reprobed to show that the total level of Akt $(A k t)$ remained constant. B, Quantitation of Akt phosphorylation by densitometric analysis of pAkt Western blots. Serum withdrawal and serum withdrawal together with MK-801 significantly decreased Akt phosphorylation compared with control washed neurons $(p<0.0001$, ANOVA). Data represent averages of duplicate determinations in three independent experiments. Error bars are SEM.

activity (Franke et al., 1997). As anticipated, serum deprivation or serum deprivation plus MK-801 reduced Akt phosphorylation, indicative of PI-3 kinase inactivation (Fig. 3). LY294002 at $30 \mu \mathrm{M}$ almost completely inhibited PI-3 kinase (Fig. 3).

Inhibition of PI-3 kinase leads to activation of GSK3 $\beta$ in PC12 and other non-neuronal cells (Cross et al., 1995; Moule et al., 1997; Pap and Cooper, 1998). To determine whether this is also the case in primary cultured postmitotic neurons, GSK3 $\beta$ activity was measured by an immune complex kinase assay. Serum deprivation or serum deprivation plus MK-801 caused a statistically significant $(p<0.0001)$ activation of GSK3 $\beta$ compared with control washed neurons (Fig. $4 A$ ). Similarly, direct inhibition of PI-3 kinase by LY294002 also activated GSK3 $\beta$ in cortical neurons (Fig. $4 B$ ). In all three paradigms, GSK3 $\beta$ was activated $75-100 \%$ relative to control treated neurons, its activity remained elevated for at least $6 \mathrm{hr}$ after the initial treatment, and GSK3 $\beta$ activation preceded the peak of morphological changes associated with apoptosis (36-72 hr). These data suggest that inhibition of PI-3 kinase and subsequent activation of GSK3 $\beta$ may contribute to neuronal apoptosis induced by trophic withdrawal. 
A.

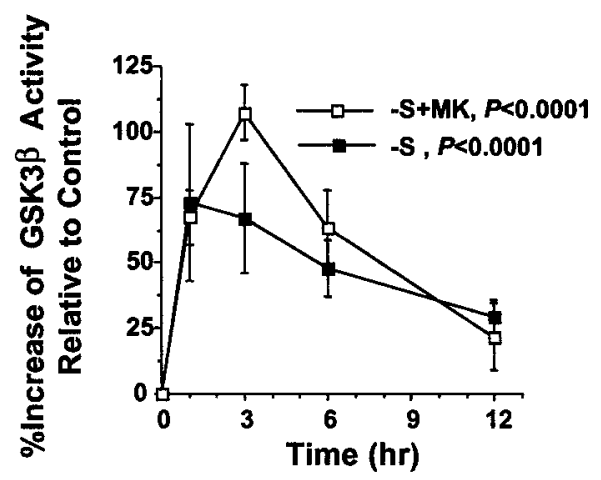

B.

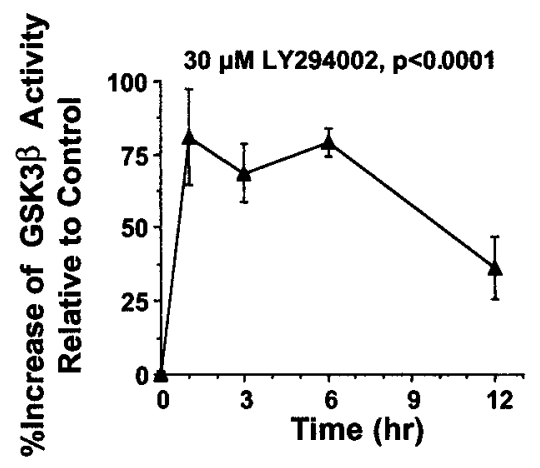

Figure 4. Activation of GSK3 $\beta$ in cortical neurons after trophic deprivation. Cortical neurons were treated as described in Figure 3. A, Serum withdrawal in the absence $(-S)$ or presence of MK-801 $(-\mathrm{S}+M K)$ significantly activated GSK3 $\beta$ compared with control washed neurons $(p<0.0001$, ANOVA). $B$, GSK3 $\beta$ was activated in neurons by treatment with LY294002 ( $p<0.0001$, ANOVA). Results in all panels are averages of duplicate determinations in three independent experiments. Error bars are SEM.

\section{BDNF suppresses GSK3 $\beta$ activation and protects cortical neurons from apoptosis after trophic withdrawal}

If trophic withdrawal-induced apoptosis is mediated by inhibition of PI-3 kinase and subsequent activation of GSK3 $\beta$, then factors that activate PI-3 kinase might prevent GSK3 $\beta$ activation and apoptosis. We reported earlier that brain-derived neurotrophic factor (BDNF) activates PI-3 kinase in cultured cortical neurons and protects these neurons from serum withdrawal-induced apoptosis (Hetman et al., 1999). Here, we tested whether BDNF can also block cortical neuron apoptosis after serum deprivation plus MK-801 and whether the neuroprotective effect of BDNF correlated with activation of PI-3 kinase and inhibition of GSK3 $\beta$.

Cortical neurons were treated with serum deprivation plus 10 $\mu \mathrm{M}$ M K-801 to induce apoptosis (Fig. $5 A$ ). Approximately $50 \%$ of cells underwent apoptosis $24 \mathrm{hr}$ after the treatment. However, only $20 \%$ of the cells were apoptotic in the presence of BDNF; the neural protection afforded by BDNF was primarily reversed by cotreatment with LY294002, suggesting a role for the PI-3 kinase in BDNF protection against apoptosis induced by serum deprivation plus MK-801 (Fig. 5A). Moreover, BDNF increased Akt phosphorylation (Fig. $5 B, C$ ) and prevented GSK3 $\beta$ activation (Fig. $5 D$ ) after serum deprivation plus MK-801 treatment. These data are consistent with the hypothesis that inhibition of GSK3 $\beta$ activity may be one of the anti-apoptotic mechanisms used by the PI-3 kinase pathway.

\section{Direct inhibition of GSK3 $\beta$ protects cortical neurons from trophic withdrawal-induced apoptosis}

To determine whether GSK3 $\beta$ activation is necessary for trophic withdrawal-induced apoptosis, we transiently transfected cortical neurons with an inhibitory GSK3 $\beta$ binding protein (GBPwt) (Yost et al., 1998) and examined the effect of blocking GSK3 $\beta$ activation on neuronal apoptosis (Fig. 6). In control experiments, neurons were transfected with an inactive GBP mutant (GBPmt), which does not bind or inhibit GSK3 $\beta$ (Yost et al., 1998). Expression of the wild-type or mutant GBP was confirmed by immunocytochemistry (data not shown). Expression of the wildtype or mutant GBP did not significantly affect the rate of basal cell death without apoptotic treatment (Fig. 6). However, transfection of neurons with GBPwt significantly protected them from apoptosis induced by serum deprivation, serum deprivation together with MK-801 treatment, or treatment with LY294002 (Fig. 6B).

We also transiently transfected cortical neurons with a kinase dead dominant negative form of GSK3 $\beta$ (GSK3 $\beta \mathrm{dn}$ ) (Dominguez et al., 1995) and examined its effect on neuronal apoptosis (Fig. 7). In control experiments, neurons were transfected with the cloning vector $\mathrm{pEF} 1 \alpha$. Transfection with GSK $3 \beta \mathrm{dn}$ or the vector had no effect on basal cell death without any treatment. In contrast, expression of GSK3 $\beta \mathrm{dn}$ caused a statistically significant reduction in apoptosis triggered by serum deprivation, serum deprivation plus MK-801 treatment, or treatment with LY294002 $\left({ }^{*} p<0.01 ;{ }^{* *} p<0.0001\right)$. These data suggest that activation of GSK3 $\beta$ contributes to apoptosis induced by trophic deprivation.

\section{Activation of GSK3 $\beta$ is sufficient to induce cortical neuron apoptosis}

If trophic withdrawal-induced apoptosis in cortical neurons is mediated by activation of GSK $3 \beta$, then direct and selective activation of GSK3 $\beta$ might be sufficient to induce apoptosis. Therefore, cortical neurons were transfected with plasmids encoding either the wild-type or a kinase dead dominant negative mutant of GSK3 $\beta$ (Dominguez et al., 1995). The corresponding cloning vector $(\mathrm{pEF} 1 \alpha)$ was used as a control. Transfection of neurons with the wild-type but not the kinase dead mutant form of GSK3 $\beta$ significantly increased apoptosis (Fig. 8). Furthermore, apoptosis induced by expression of GSK $3 \beta$ was inhibited by BDNF in a PI3 kinase-dependent manner (data not shown). Thus, direct and selective activation of GSK3 $\beta$ is sufficient to induce apoptosis in cortical neurons.

\section{Degradation of $\beta$-catenin is not critical for cortical neuron apoptosis induced by withdrawal of trophic support}

Activated GSK3 $\beta$ leads to phosphorylation and subsequent degradation of $\beta$-catenin (Miller and Moon, 1996). This is one of the best characterized biochemical events downstream of GSK3 $\beta$ activation (Miller and Moon, 1996). To determine whether $\beta$-catenin degradation is important for GSK3 $\beta$-induced apoptosis, we transiently transfected cortical neurons with either wildtype or a mutant form of $\beta$-catenin in which all four GSK3 $\beta$ targeted serine residues were mutated to alanines (Miller and Moon, 1996). This mutant $\beta$-catenin is very stable and is resistant to GSK3 $\beta$-induced degradation (Miller and Moon, 1996). Our results confirmed this observation. Expression of the wild-type or mutant $\beta$-catenin before apoptotic treatment was demonstrated by immunocytochemistry (Fig. 9A). Furthermore, the mutant $\beta$-catenin protein was indeed stable, whereas the wild-type 
A.

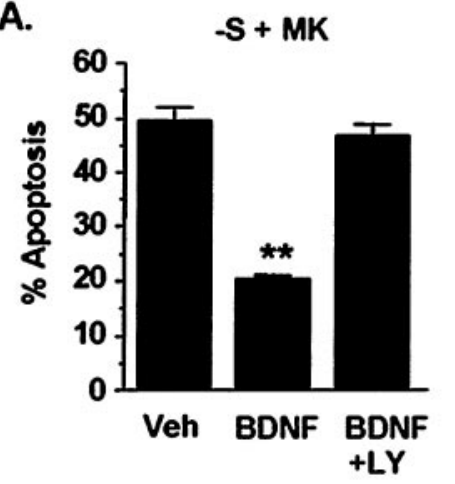

C.

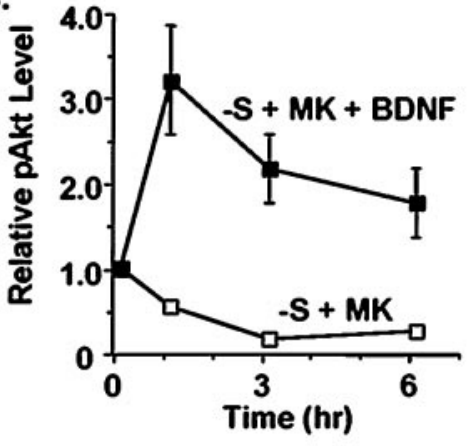

B.

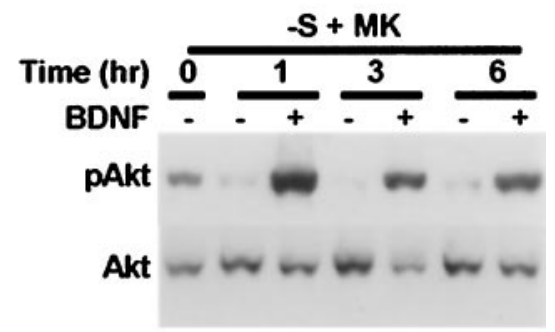

Figure 5. BDNF inhibits apoptosis, which correlates with activation of PI-3 kinase and inhibition of GSK3 $\beta$ in trophic-deprived neurons. Cortical neurons were treated with serum deprivation plus $10 \mu \mathrm{M}$ MK$801(-\mathrm{S}+M K)$ in the presence or absence of $10 \mathrm{ng} / \mathrm{ml}$ BDNF. $A$, BDNF protected cortical neurons from apoptosis compared with vehicle treated controls (Veh) $\left({ }^{*} p<0.0001\right.$, ANOVA). Apoptosis was scored $24 \mathrm{hr}$ after the treatment. Addition of $30 \mu \mathrm{M}$ LY294002 $(B D N F+L Y)$ reversed the protective effect of BDNF, suggesting a requirement for PI-3 kinase activity in BDNF protection. $B$, BDNF induced Akt phosphorylation at Ser-473, indicative of PI-3 kinase activation. Akt phosphorylation ( $p A k t)$ was examined by Western analysis at indicated times after BDNF treatment. The blots were reprobed to show that the total level of Akt (Akt) remained constant. $C$, Quantitation of Akt phosphorylation by densitometric analysis of pAkt Western blots. $D$, BDNF significantly inhibited GSK3 $\beta$ activity in neurons deprived of trophic support ( $p<0.001$, ANOVA). Results in all panels are averages of triplicate determinations in at least two independent experiments. Error bars are SEM. $\beta$-catenin protein was undetectable in these neurons after any of the three apoptotic treatments (data not shown). These results are consistent with the notion that apoptotic treatments cause activation of endogenous GSK $3 \beta$ and subsequent degradation of the wild-type but not mutant $\beta$-catenin. If $\beta$-catenin degradation is important for GSK $3 \beta$-induced apoptosis, then overexpression of the stable $\beta$-catenin mutant might protect neurons from apoptosis. However, expression of either the wild-type or the mutant $\beta$-catenin had no significant effect on cortical neuron apoptosis after serum deprivation, serum deprivation together with MK801 treatment, or treatment with LY294002 (Fig. 9B). Therefore, stabilization of $\beta$-catenin is ineffective in blocking GSK3 $\beta$ mediated apoptosis, suggesting that $\beta$-catenin is not the critical substrate by which GSK3 $\beta$ triggers neuron death.

\section{DISCUSSION}

The goal of this study was to test the hypothesis that inhibition of GSK $3 \beta$ through PI-3 kinase pathway is one of the downstream mechanisms that mediate PI-3 kinase-dependent neuronal survival. Using cultured cortical neurons, we identified three apoptotic paradigms in which PI-3 kinase activity was suppressed while GSK $3 \beta$ was activated. These include serum deprivation, serum deprivation with inhibition of NMDA receptors, or treatment with a PI-3 kinase inhibitor LY294002. Our data demonstrate that apoptosis induced by all three paradigms was accompanied by inhibition of PI-3 kinase, as well as activation of GSK $3 \beta$. Furthermore, direct inhibition of GSK3 $\beta$ by expression of either GBP, a specific and potent inhibitor of GSK3 $\beta$ (Yost et al., 1998), or a dominant negative mutant form of GSK3 $\beta$ (Dominguez et al., 1995) partially prevented cell death induced by all three treatments. In contrast, expression of wild-type GSK $3 \beta$ alone was sufficient to induce cortical neuron apoptosis, even in the presence of serum. Moreover, BDNF-mediated protection against trophic deprivation required PI-3 kinase activity and correlated with inhibition of GSK $3 \beta$. GSK $3 \beta$ is the substrate of Akt (Cross et al., 1995; Moule et al., 1997), although it might also be inhibited by other PI-3 kinase-dependent pathways (Delcommenne et al., 1998; Kobayashi and Cohen, 1999). Although we cannot distinguish between these two possibilities, our results strongly suggest that GSK $3 \beta$ is an important inducer of neuronal apoptosis and that PI-3 kinase-promoted neuronal survival may involve negative regulation of GSK3 $\beta$.

Pap and Cooper (1998) reported that nerve growth factor leads to GSK $3 \beta$ inactivation via the PI-3 kinase pathway. Furthermore, inhibition of PI-3 kinase by either LY294002 treatment or expression of dominant negative mutants interfering with PI-3 kinaseAkt pathway induces apoptosis in Rat1 fibroblasts and neuronallike PC12 cells, whereas inhibition of GSK $3 \beta$ prevented apoptosis (Pap and Cooper, 1998). Together with our findings, these data suggest that inhibition of GSK3 $\beta$ activity by the PI-3 kinase signaling pathway may be a general mechanism for survival of neurons and non-neuronal cells. Activation of the PI-3 kinaseAkt signal transduction system may promote survival through several mechanisms, including inhibition of GSK3 $\beta$, phosphorylation of proapoptotic proteins Bad, FKHRL1 (Datta et al., 1997; del Peso et al., 1997; Brunet et al., 1999), and phosphorylation of caspase-9 (Cardone et al., 1998). This suggests that multiple mechanisms may work in parallel downstream from PI-3 kinase to suppress apoptosis.

The mechanism for induction of apoptosis by GSK3 $\beta$ remains undefined. GSK3 $\beta$ phosphorylates four serine residues at the $\mathrm{N}$-terminal region of $\beta$-catenin and causes $\beta$-catenin degradation (Miller and Moon, 1996; Yost et al., 1996). It has been proposed that destabilization of $\beta$-catenin potentiates neuronal apoptosis induced by $\beta$-amyloid peptide (Z. Zhang et al., 1998). This suggested the interesting hypothesis that GSK3 $\beta$-induced apoptosis involves degradation of $\beta$-catenin. However, our data do 
A.
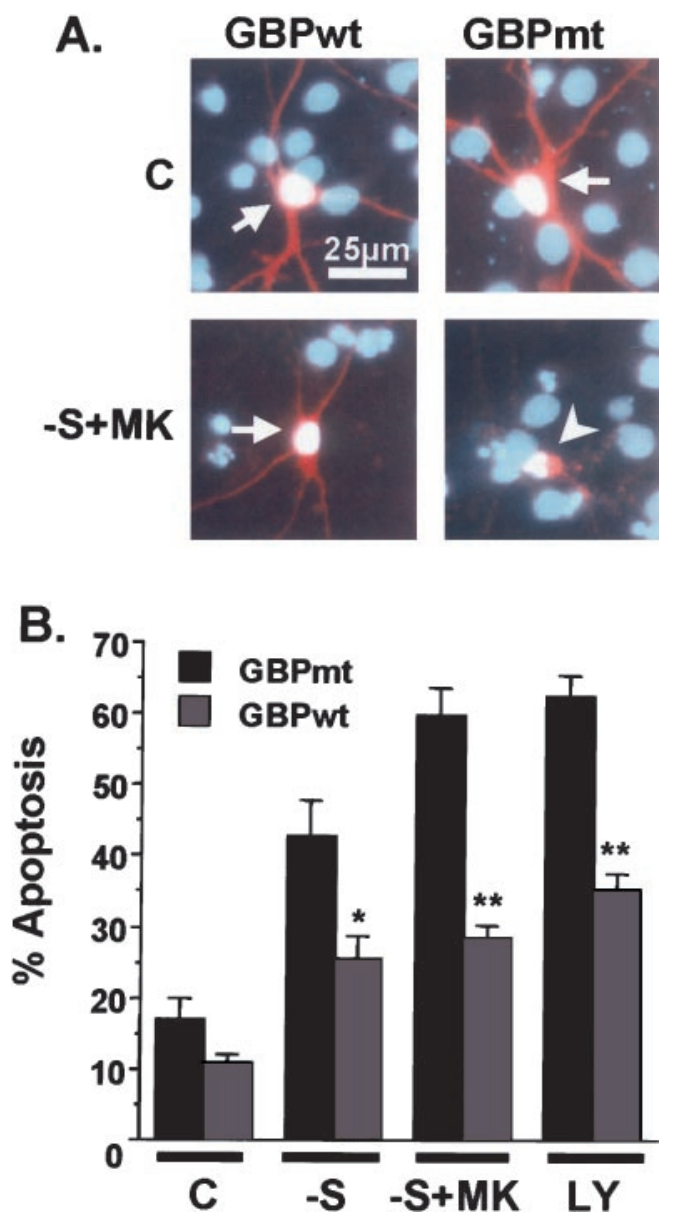

Figure 6. Expression of GBP, a GSK3 $\beta$ inhibitor, protects trophicdeprived neurons from apoptosis. Cortical neurons were transfected with $4 \mu \mathrm{g}$ of plasmid DNA encoding GBPwt or GBPmt, which is unable to bind or inhibit GSK3 $\beta$. Cells were also cotransfected with an expression vector encoding $\beta$-galactosidase ( $2 \mu \mathrm{g})$ as a marker for transfection. Three days after transfection, neurons were either fixed directly $(C)$ or treated with serum deprivation $(-S)$, serum deprivation with $10 \mu \mathrm{M}$ MK-801 $(-S+M K)$, or $30 \mu \mathrm{M}$ LY294002 $(L Y)$ for $24 \mathrm{hr}$. A, Representative immunofluorescence photomicrographs of cortical neurons. Transfected cells were identified by $\beta$-galactosidase immunostaining (red cells). To reveal nuclear morphology, cells were counter-stained with Hoechst 33258 (blue). Arrows indicate transfected cells with healthy morphology. The arrowhead identifies a transfected cell with apoptotic morphology after serum deprivation combined with MK-801 treatment. $B$, Expression of the wild-type but not the mutant GBP inhibited apoptosis. Apoptosis in the transfected cell population was quantitated. Data are averages of duplicate determinations in three independent experiments. At least 1000 transfected cells were scored for each data point. Error bars are SEM. Statistically significant differences are indicated $\left({ }^{*} p<0.01 ;{ }^{* *} p<0.0001\right.$, one-way ANOVA, factor-transfected plasmid).

not support this general hypothesis because overexpression of wild-type or a stable mutant form of $\beta$-catenin did not rescue cortical neuron from trophic deprivation-induced apoptosis.

In addition to $\beta$-catenin and glycogen synthase, several other substrates for GSK $3 \beta$ have been identified, some of which are worth consideration as candidate mediators of GSK $3 \beta$-induced cell death. For example, mitochondrial pyruvate dehydrogenase is phosphorylated and inhibited by GSK3 $\beta$; the subsequent metabolic failure might cause neuron death (Hoshi et al., 1996). GSK $3 \beta$ also phosphorylates insulin receptor substrate 1 (IRS-1) and converts IRS-1 into an inhibitor of insulin receptor tyrosine kinase activity (Eldar-Finkelman and Krebs, 1997). Because

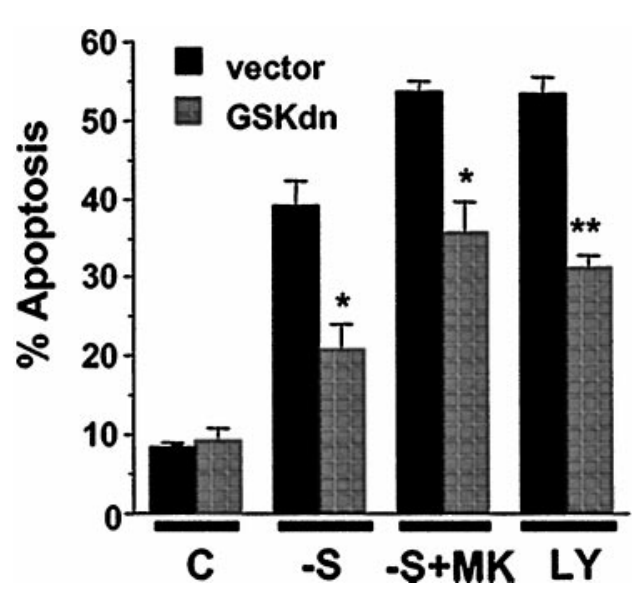

Figure 7. Expression of a dominant negative mutant form of GSK3 $\beta$ protects trophic-deprived neurons from apoptosis. Cortical neurons were transfected with $4 \mu \mathrm{g}$ of plasmid DNA encoding a dominant negative form of rat GSK3 $\beta(G S K d n)$. The empty cloning vector $\mathrm{pEF} 1 \alpha$ was used as control (vector). Cells were also cotransfected with an expression vector encoding $\beta$-galactosidase $(2 \mu \mathrm{g})$ as a marker for transfection. Three days after transfection, neurons were either fixed directly $(C)$ or treated with serum deprivation $(-S)$, serum deprivation with $10 \mu \mathrm{M}$ MK-801 $(-S+M K)$, or $30 \mu \mathrm{M}$ LY294002 $(L Y)$ for $24 \mathrm{hr}$. Apoptosis in the transfected cell population was quantitated. Expression of the dominant negative GSK $3 \beta$ inhibited apoptosis. Data are averages of duplicate determinations in three independent experiments. At least 1000 transfected cells were scored for each data point. Error bars are SEM. Statistically significant differences are indicated $\left({ }^{*} p<0.01 ;{ }^{*} p<0.0001\right.$, one-way ANOVA, factor-transfected plasmid).

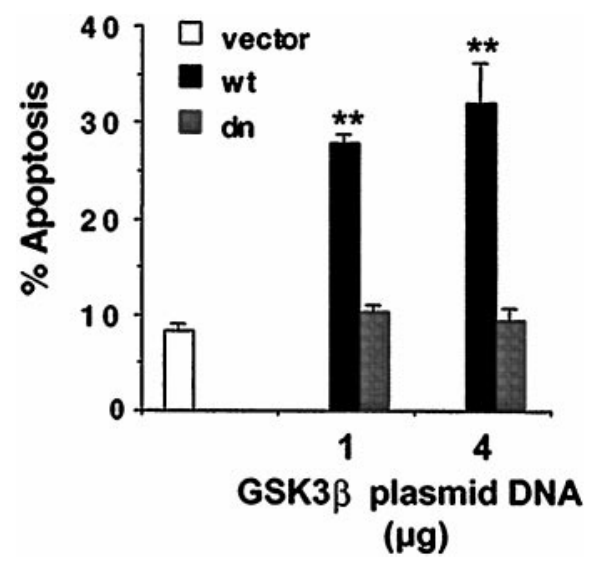

Figure 8. Activation of GSK3 $\beta$ is sufficient to induce neuronal apoptosis. Cortical neurons were transfected with 1 or $4 \mu \mathrm{g}$ of plasmid DNA encoding either wild-type ( $w t$ ) or a dominant negative mutant of GSK3 $\beta$ $(d n)$. Cells were also cotransfected with $2 \mu \mathrm{g}$ of plasmid DNA encoding $\beta$-galactosidase as a marker for transfection. The cloning vector $\mathrm{pEF} 1 \alpha$ was used as a control (vector) and to supplement the total DNA to $6 \mu \mathrm{g}$ in each case. Three days after transfection, cells were fixed and immunostained. Apoptosis in transfected cell population ( $\beta$-galactosidasepositive) was scored. Data are averages of duplicate determinations in three independent experiments. At least 1000 transfected cells were scored for each data point. Error bars are SEM. Statistical analysis was performed as described in Figure $7\left({ }^{* *} p<0.0001\right)$.

IRS-1 is critical in the signaling of insulin and insulin-like growth factor and both factors promote neuronal survival, phosphorylation of IRS- 1 by GSK $3 \beta$ may contribute to GSK $3 \beta$-induced cell death. Furthermore, GSK3 $\beta$ phosphorylates microtubuleassociated protein tau into Alzheimer's disease-like forms (PHtau) found in tangles (Hanger et al., 1992; Mandelkow et al., 1992; 
A.
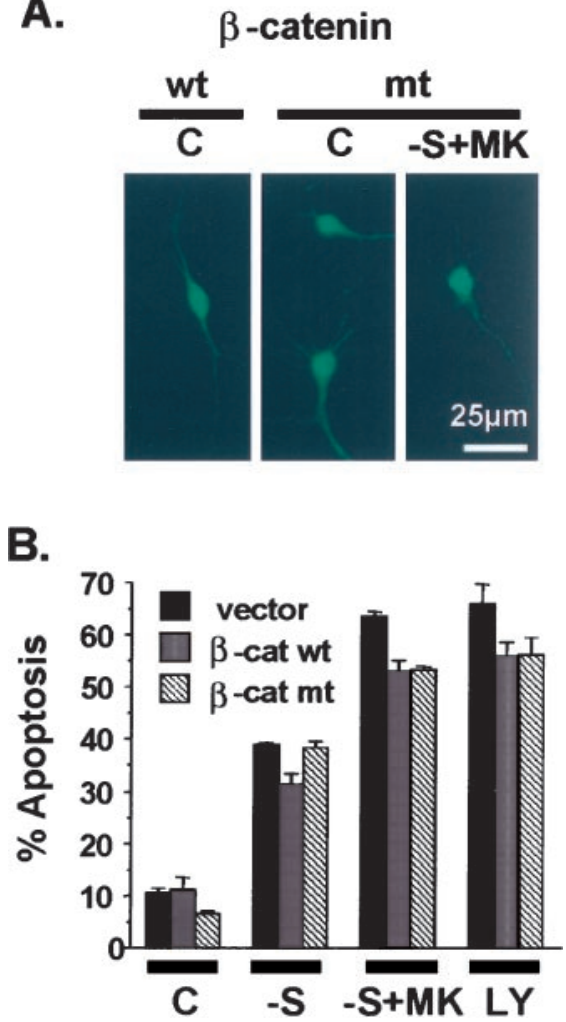

Figure 9. Expression of $\beta$-catenin does not protect cortical neurons from apoptosis induced by trophic withdrawal. Cortical neurons were transfected with $4 \mu \mathrm{g}$ of plasmid DNA encoding the wild-type ( $\beta$-cat wt) or a mutant form $(\beta$-cat $m t)$ of $\beta$-catenin. The cloning vector was used as a control (vector). All four of the serine residues in $\beta$-catenin, which are targeted by GSK3 $\beta$, were mutated to alanines in the mutant form of $\beta$-catenin, which is stable and not subject to GSK $3 \beta$-induced degradation. Cells were also cotransfected with an expression vector encoding $\beta$-galactosidase $(2 \mu \mathrm{g})$ as a marker for transfection. Two days after transfection, neurons were either fixed directly $(C)$ or treated with serum deprivation $(-S)$, serum deprivation with $10 \mu \mathrm{M}$ MK-801 $(-S+M K)$, or $30 \mu \mathrm{M}$ LY294002 ( $L Y)$ for $24 \mathrm{hr}$. A, Representative photomicrographs depicting immunostaining with 9E10 antibody to detect transfected Myctagged $\beta$-catenin. $B$, Apoptosis in the transfected cell population $(\beta$ galactosidase-stained cells) was quantitated. Data are averages of duplicate determinations. Similar results were obtained in two independent experiments. At least 350 transfected cells were scored for each condition. Error bars are SEM.

Ishiguro et al., 1993; Mulot et al., 1994). The appearance of $\mathrm{PH}$-tau is associated with early alterations in neurites associated with Alzheimer's disease (Goedert et al., 1995). Tau phosphorylation by GSK3 $\beta$ may cause axonal dysfunction and trigger neuronal apoptosis. Regardless of the downstream target, our data strongly indicate that inhibition of GSK $3 \beta$ by PI-3 kinase is an important mechanism for neuronal survival.

Our finding that serum withdrawal-induced apoptosis of cortical neurons is potentiated by NMDA antagonists suggests that optimal cortical neuron survival requires both trophic factors and NMDA receptor activity. The role of NMDA receptor activity in supporting neuronal survival has also been demonstrated in cultured cerebellar granule neurons (F. X. Z hang et al., 1998; Bhave et al., 1999) and in forebrain cortical neurons in vivo (Ikonomidou et al., 1999). Collectively, these findings support the notion that neuronal survival depends on both the availability of peptide trophic factors and neuronal activity.

In summary, we have discovered that cortical neuron apoptosis induced by trophic withdrawal is mediated in part by GSK3 $\beta$ activation. Our findings add GSK $3 \beta$ to the list of potential drug targets for pharmacotherapy of neurodegenerative disorders and suggest that GSK3 $\beta$ may play a critical role in neuronal apoptosis.

\section{REFERENCES}

Bhave SV, Ghoda L, Hoffman PL (1999) Brain-derived neurotrophic factor mediates the anti-apoptotic effect of NMDA in cerebellar granule neurons: signal transduction cascades and site of ethanol action. J Neurosci 19:3277-3286.

Brunet A, Bonni A, Zigmond MJ, Lin MZ, Juo P, Hu LS, Anderson MJ, Arden KC, Blenis J, Greenberg ME (1999) Akt promotes cell survival by phosphorylating and inhibiting a Forkhead transcription factor. Cell 96:857-868.

Cardone MH, Roy N, Stennicke HR, Salvesen GS, Franke TF, Stanbridge E, Frisch S, Reed JC (1998) Regulation of cell death protease caspase- 9 by phosphorylation. Science 282:1318-1321.

Castellino AM, Chao MV (1996) Trans-signaling by cytokine and growth factor receptors. Cytokine Growth Factor Rev 7:297-302.

Chao M, Casaccia-Bonnefil P, Carter B, Chittka A, Kong H, Yoon SO (1998) - Neurotrophin receptors: mediators of life and death. Brain Res Brain Res Rev 26:295-301.

Cherrington JM, Mocarski ES (1989) Human cytomegalovirus iel transactivates the $\alpha$ promoter-enhancer via an 18-base-pair repeat element. J Virol 63:1435-1440.

Cross DA, Alessi DR, Cohen P, Andjelkovich M, Hemmings BA (1995) Inhibition of glycogen synthase kinase- 3 by insulin mediated by protein kinase B. Nature 378:785-789.

Crowder RJ, Freeman RS (1998) Phosphatidylinositol 3-kinase and Akt protein kinase are necessary and sufficient for the survival of nerve growth factor-dependent sympathetic neurons. J Neurosci 18:2933-2943.

D'Mello SR, Borodezt K, Soltoff SP (1997) Insulin-like growth factor and potassium depolarization maintain neuronal survival by distinct pathways: possible involvement of PI 3-kinase in IGF-1 signaling. J Neurosci 17:1548-1560.

D’Mello SR, Galli C, Ciotti T, Calissano P (1993) Induction of apoptosis in cerebellar granule neurons by low potassium: inhibition of death by insulin-like growth factor I and cAMP. Proc Natl Acad Sci USA 90:10989-10993.

Datta SR, Dudek H, Tao X, Masters S, Fu HA, Gotoh Y, Greenberg ME (1997) Akt phosphorylation of BAD couples survival signals to the cell-intrinsic death machinery. Cell 91:231-241.

Datta SR, Greenberg ME (1998) Molecular mechanisms of neuronal survival and apoptosis. In: Hormones signaling (O’Malley B, ed), pp 257-306. San Diego: Academic.

del Peso L, GonzalezGarcia M, Page C, Herrera R, Nunez G (1997) Interleukin-3-induced phosphorylation of BAD through the protein kinase Akt. Science 278:687-689.

Delcommenne M, Tan C, Gray V, Rue L, Woodgett J, Dedhar S (1998) Phosphoinositide-3-OH kinase-dependent regulation of glycogen synthase kinase 3 and protein kinase B/AKT by the integrin-linked kinase. Proc Natl Acad Sci USA 95:11211-11216.

Dominguez I, Itoh K, Sokol SY (1995) Role of glycogen synthase kinase 3 beta as a negative regulator of dorsoventral axis formation in Xenopus embryos. Proc Natl Acad Sci USA 92:8498-8502.

Dudek H, Datta SR, Franke TF, Birnbaum MJ, Yao RJ, Cooper GM, Segal RA, Kaplan DR, Greenberg ME (1997) Regulation of neuronal survival by the serine-threonine protein kinase Akt. Science 275:661-665.

Eldar-Finkelman H, Krebs EG (1997) Phosphorylation of insulin receptor substrate 1 by glycogen synthase kinase 3 impairs insulin action. Proc Natl Acad Sci USA 94:9660-9664.

Estus S (1998) Gene induction and neuronal apoptosis. In: Neuroprotective signal transduction (Mattson MP, ed), pp 83-94. Totowa, NJ: Humana.

Franke TF, Kaplan DR, Cantley LC (1997) PI3K: downstream AKTion blocks apoptosis. Cell 88:435-437.

Goedert M, Spillantini MG, Jakes R, Crowther RA, Vanmechelen E, Probst A, Gotz J, Burki K, Cohen P (1995) Molecular dissection of the paired helical filament. Neurobiol Aging 16:325-334.

Hanger DP, Hughes K, Woodgett JR, Brion JP, Anderton BH (1992) Glycogen synthase kinase-3 induces Alzheimer's disease-like phosphorylation of tau: generation of paired helical filament epitopes and neuronal localisation of the kinase. Neurosci Lett 147:58-62. 
Hemmings BA (1997) Signal transduction-Akt signaling: linking membrane events to life and death decisions. Science 275:628-630.

Hetman M, Kanning K, Smith-Cavanaugh JE, Xia Z (1999) Neuroprotection by brain-derived neurotrophic factor is mediated by extracellular-signal-regulated kinase and phosphatidylinositol-3 kinase. J Biol Chem 274:22569-22580.

Hockenbery D, Nuñez G, Millman C, Schreiber RD, Korsmeyer SJ (1990) Bcl-2 is an inner mitochondrial membrane protein that blocks programmed cell death. Nature 348:334-336.

Hoshi M, Takashima A, Noguchi K, Murayama M, Sato M, Kondo S, Saitoh Y, Ishiguro K, Hoshino T, Imahori K (1996) Regulation of mitochondrial pyruvate dehydrogenase activity by tau protein kinase I/glycogen synthase kinase 3beta in brain. Proc Natl Acad Sci USA 93:2719-2723.

Ikonomidou C, Bosch F, Miksa M, Bittigau P, Vockler J, Dikranian K, Tenkova TI, Stefovska V, Turski L, Olney JW (1999) Blockade of NMDA receptors and apoptotic neurodegeneration in the developing brain. Science 283:70-74.

Ishiguro K, Shiratsuchi A, Sato S, Omori A, Arioka M, Kobayashi S, Uchida T, Imahori K (1993) Glycogen synthase kinase 3 beta is identical to tau protein kinase I generating several epitopes of paired helical filaments. FEBS Lett 325:167-172.

Kauffmann-Zeh A, RodriguezViciana P, Ulrich E, Gilbert C, Coffer P, Downward J, Evan G (1997) Suppression of c-Myc-induced apoptosis by Ras signalling through PI(3)K and PKB. Nature 385:544-548.

Kobayashi T, Cohen P (1999) Activation of serum- and glucocorticoidregulated protein kinase by agonists that activate phosphatidylinositide 3-kinase is mediated by 3- phosphoinositide-dependent protein kinase-1 (PDK1) and PDK2. Biochem J 339:319-328.

Koh J-Y, Gwag BJ, Lobner D, Choi DW (1995) Potentiated necrosis of cultured cortical neurons by neurotrophins. Science 268:573-575.

Kulik G, Klippel A, Weber MJ (1997) Antiapoptotic signalling by the insulin-like growth factor I receptor, phosphatidylinositol 3-kinase, and Akt. Mol Cell Biol 17:1595-1606.

Levi-Montalcini R, Booker B (1960) Destruction of sympathetic ganglia in mammals by an antisera to nerve growth factor protein. Proc Natl Acad Sci USA 46:384-391.

Mandelkow EM, Drewes G, Biernat J, Gustke N, Van Lint J, Vandenheede JR, Mandelkow E (1992) Glycogen synthase kinase-3 and the Alzheimer-like state of microtubule-associated protein tau. FEBS Lett 314:315-321.

Miller JR, Moon RT (1996) Signal transduction through beta-catenin and specification of cell fate during embryogenesis. Genes Dev $10: 2527-2539$.

Miller TM, Tansey MG, Johnson EM, Creedon DJ (1997) Inhibition of phosphatidylinositol 3-kinase activity blocks depolarization- and insulin-like growth factor I-mediated survival of cerebellar granule cells. J Biol Chem 272:9847-9853.

Moule SK, Welsh GI, Edgell NJ, Foulstone EJ, Proud CG, Denton RM (1997) Regulation of protein kinase B and glycogen synthase kinase-3 by insulin and beta-adrenergic agonists in rat epididymal fat cells. Activation of protein kinase $\mathrm{B}$ by wortmannin-sensitive and -insensitive mechanisms. J Biol Chem 272:7713-7719.

Mulot SF, Hughes K, Woodgett JR, Anderton BH, Hanger DP (1994) PHF-tau from Alzheimer's brain comprises four species on SDS-PAGE which can be mimicked by in vitro phosphorylation of human brain tau by glycogen synthase kinase-3 beta. FEBS Lett 349:359-364.

Murga C, Laguinge L, Wetzker R, Cuadrado A, Gutkind JS (1998) Activation of Akt/protein kinase B by G protein-coupled receptors. A role for alpha and beta gamma subunits of heterotrimeric $G$ proteins acting through phosphatidylinositol-3-OH kinase gamma. J Biol Chem 273:19080-19085.

Pap M, Cooper GM (1998) Role of glycogen synthase kinase-3 in the phosphatidylinositol 3-kinase/Akt cell survival pathway. J Biol Chem 273:19929-19932.

Park DS, Stefanis L, Greene LA (1997) Ordering the multiple pathways of apoptosis. Trends Cardiovasc Med 7:294-301.

Parrizas M, Saltiel AR, LeRoith D (1997) Insulin-like growth factor 1 inhibits apoptosis using the phosphatidylinositol 3'-kinase and mitogenactivated protein kinase pathways. J Biol Chem 272:154-161.

Philpott KL, McCarthy MJ, Klippel A, Rubin LL (1997) Activated phosphatidylinositol 3-kinase and Akt kinase promote survival of superior cervical neurons. J Cell Biol 139:809-815.

Pierce SB, Kimelman D (1995) Regulation of Spemann organizer formation by the intracellular kinase Xgsk-3. Development 121:755-765.

Raff MC, Barres BA, Burne J, Coles HS, Ishizaki Y, Jacobson MD (1993) Programmed cell death and the control of cell survival: lessons from the nervous system. Science 262:695-700.

Stefanis L, Burke RE, Greene LA (1997) Apoptosis in neurodegenerative disorders. Curr Opin Neurol 10:299-305.

Vlahos CJ, Matter WF, Hui KY, Brown RF (1994) A specific inhibitor of phosphatidylinositol 3-kinase, 2-(4-morpholinyl)-8-phenyl-4H-1benzopyran-4-one (LY294002). J Biol Chem 269:5241-5248.

Wang QM, Fiol CJ, DePaoli-Roach AA, Roach PJ (1994) Glycogen synthase kinase- 3 beta is a dual specificity kinase differentially regulated by tyrosine and serine/threonine phosphorylation. J Biol Chem 269:14566-14574.

Watkins JC, Collingridge GL (1989) The NMDA receptor. Oxford: Oxford UP.

Xia Z, Dickens M, Raingeaud J, Davis RJ, Greenberg ME (1995) Opposing effects of ERK and JNK-p38 MAP kinases on apoptosis. Science 270:1326-1331.

Xia Z, Dudek H, Miranti CK, Greenberg ME (1996) Calcium influx via the NMDA receptor induces immediate early gene transcription by a MAP kinase/ERK-dependent mechanism. J Neurosci 16:5425-5436.

Yamada M, Ohnishi H, Sano S, Nakatani A, Ikeuchi T, Hatanaka H (1997) Insulin receptor substrate (IRS)-1 and IRS-2 are tyrosinephosphorylated and associated with phosphatidylinositol 3-kinase in response to brain-derived neurotrophic factor in cultured cerebral cortical neurons. J Biol Chem 272:30334-30339.

Yao R, Cooper GM (1995) Requirement for phosphatidylinositol-3 kinase in the prevention of apoptosis by nerve growth factor. Science 267:2003-2006.

Yost C, Farr GHR, Pierce SB, Ferkey DM, Chen MM, Kimelman D (1998) GBP, an inhibitor of GSK-3, is implicated in Xenopus development and oncogenesis. Cell 93:1031-1041.

Yost C, Torres M, Miller JR, Huang E, Kimelman D, Moon RT (1996) The axis-inducing activity, stability, and subcellular distribution of beta-catenin is regulated in Xenopus embryos by glycogen synthase kinase 3. Genes Dev 10:1443-1454.

Zhang FX, Rubin R, Rooney TA (1998) N-Methyl-D-aspartate inhibits apoptosis through activation of phosphatidylinositol 3-kinase in cerebellar granule neurons. A role for insulin receptor substrate-1 in the neurotrophic action of $N$-methyl-D- aspartate and its inhibition by ethanol. J Biol Chem 273:26596-26602.

Zhang Z, Hartmann H, Do VM, Abramowski D, Sturchler-Pierrat C, Staufenbiel M, Sommer B, van de Wetering M, Clevers H, Saftig P, De Strooper B, He X, Yankner BA (1998) Destabilization of beta-catenin by mutations in presenilin-1 potentiates neuronal apoptosis. Nature 395:698-702. 